\title{
The Effectiveness of Cognitive-Behavioural Interventions at Increasing Adherence to Physical Activity in Mental Health Populations: A Systematic Review
}

\section{$\underline{\text { ABSTRACT }}$}

Objective: There is growing global evidence for stark inequalities in the physical health status and life-expectancy of people with a mental health diagnosis. In most cases, physical activity (PA) is one of the most effective methods of maintaining physical and mental health. However, people with mental health challenges are less likely to adhere to recommended levels of PA, leading to a vicious cycle of poor physical and mental health. The objective of this paper is to assess if, and how cognitive-behavioural $(C B)$ techniques increase adherence to PA in mental health populations.

Method: Systematic review and narrative synthesis. Included studies detailed a behavioural change intervention which targeted PA using CB approaches, delivered to adults with a mental health condition as defined by DSM V or ICD-10. Adherence to the intervention AND physical activity was reported within RCT, cluster RCT, quasi-experimental, or controlled before and after study. Electronic searches conducted in MEDLINE, CINAHL, Cochrane Library (Trials), SPORTDiscus and PsycINFO.

Results: Ten studies from seven countries were synthesised. Methodologically moderate to weak, all showed adherence to the intervention to be associated with increased levels of PA. All studies reported higher than average adherence to PA in the intervention groups.

Discussion: CB interventions were associated with improved adherence to PA in international samples of people with mental health conditions. Studies adopting more robust designs are needed to quantify optimal interventions and impact, but this original synthesis is encouraging for researchers and clinicians alike looking to maximise the synergy between physical and mental health.

Registration number: CRD42017057918

DECLARATION OF INTEREST: None

Key Words: Anxiety, depression, exercise, behaviour change, interventions, physical activity 


\section{Introduction}

The aim of this review is to assess if and how cognitive behavioural (CB) techniques increase adherence to physical activity (PA) for those presenting with mental health concerns. The first section of this paper examines the evidence for the mental health benefits of physical activity. It describes the unique barriers to PA faced by those with mental illness to show that adherence is a discrete problem in this population. It goes on to suggest that cognitive behavioural approaches may help this population start and maintain physical activity. It concludes with a justification for the need to review the literature to examine the degree to which this is true.

For the purpose of review, physical activity (PA) is defined as "bodily movement produced by skeletal muscles that results in energy expenditure" (Caspersen, Powell, \& Christenson, 1985, p6). In this review, physical activity includes exercise. Exercise is defined as PA that is "planned, structured or repetitive, targeted to maintain or improve one or more components of health-related physical fitness" (WHO, 2018, webpage) such as aerobic endurance, muscular strength, muscular endurance, body composition, flexibility. The distinction is important because PA can include walking-based interventions, lifestyle improvement intervention, and non-structured exercise.

People 'diagnosed with mental health problems' are those with a diagnosis as defined by the DSM V and ICD-11 (WHO, 2019). Cognitive behavioural interventions refer to interventions that employ cognitive behavioural techniques, such as goal setting, problem-solving and homework to examine associations between thoughts, feelings and behaviour in order to elicit behaviour change.

Finally, 'adherence to PA' is inconsistently defined in the literature. Hawley-Hague, Horne, Skelton, and Todd (2016) concluded that adherence to PA should refer to one or all of the following: completion of a prescribed programme of activity (i.e. retention), attendance frequency, attendance duration, and intensity of activity. They concluded that adherence to 
PA should be defined according to the purpose of the study. Following Hawley-Hague et al (2016) the key elements of adherence to PA are defined here using the following parameters: a) completion of programme of activity or not (retention), b) proportion of sessions/classes attended (frequency), c) amount of physical activity, measured in time, during intervention (duration), d) intensity of activity during programme, and e) b to $d$ at follow-up.

\section{BACKGROUND}

Physical activity is essential for maintaining health and well-being. For example, it can reduce the risk of chronic physical diseases, such as cardiovascular disease (CVD), type 2 diabetes, hypertension, and respiratory illnesses (Naci \& loannidis, 2013). However, PA is not only beneficial for physical health. A growing body of evidence also supports the positive relationship between PA and mental health (Schuch, Vancampfort, Richards, et al., 2016). Physical activity has been shown to be an effective treatment in populations with clinical depression (Craft \& Perna, 2004; Daley, 2008). In some studies PA has been shown to be as effective as pharmacology or psychotherapies for reducing severity of depressive symptoms (Schuch, Vancampfort, Richards, et al., 2016). The UK National Institute for Health and Clinical Excellence (NICE) guidelines recommend structured physical activity as an appropriate treatment for people with mild to moderate depression (NICE, 2010).

There is less research investigating PA in patients with diagnosed anxiety disorders, however, available evidence suggests that exercise can reduce symptoms and is an acceptable treatment (Herring, Lindheimer, \& O'Connor, 2013). A review of exercise interventions for people diagnosed with schizophrenia concluded that PA could help to alleviate secondary symptoms, such as anxiety and depression, and other negative symptoms of schizophrenia (Faulkner, Gorczynski, \& Arbour-Nicitopoulos, 2013).

Engagement in PA can have a wide range of benefits for people with mental health conditions, even in the absence of objective diagnostic improvements. PA can improve 
quality of life, reduce isolation by providing opportunities for social interaction and increase the likelihood of individuals returning to 'normal' previously enjoyed activities (Crone, Heaney, \& Owens, 2009). This increasingly extensive body of evidence of the positive effects of PA and exercise on a broad range of mental health conditions has led to the recommendation that $\mathrm{PA}$ should be used as an adjunct to usual treatment for a range of conditions, including anxiety disorders, depression, substance abuse and schizophrenia (Rosenbaum et al., 2015).

However, despite these well-established benefits, people diagnosed with mental health problems are significantly less active than the general population (Nyboe \& Lund, 2013). They often face substantial illness-related barriers to PA, above and beyond those experienced by healthy individuals (Glowacki, Duncan, Gainforth, \& Faulkner, 2017). Psychotropic medicines cause weight gain and metabolic changes (Haddad, 2004), as well as other side effects such as lack of energy and motivation (Glover, Ferron, \& Whitley, 2013). On average, people with chronic mental health conditions die 10 to 25 years earlier than people without mental health conditions (WHO, 2014). As much of this mortality is linked to cardiovascular issues, it is logical to suggest that PA may be beneficial for reducing this risk (Nocon et al., 2008). The problem is that physical activity is uniquely difficult for people with mental health problems.

In the general population, adherence to PA programmes drops off after six months, with less than half the participants completing(Gidlow, Johnston, Crone, \& James, 2005; Richardson et al., 2005). In people with mental health conditions, some suggest that attrition is significantly greater (Rosenbaum et al., 2015). However, cognitive behavioural interventions have been found to be somewhat effective at increasing PA. Reviews which have looked at adherence to PA interventions in a range of populations, including people with chronic illness, elderly and obese populations (O'Halloran et al., 2014; Picorelli, Pereira, Pereira, Felício, \& Sherrington, 2014; Samdal, Eide, Barth, Williams, \& Meland, 2017), have found 
evidence to suggest that interventions which emphasize a person-centred style, facilitate self-regulation and sustained positive motivation are associated with long-term effectiveness and maintenance of behaviour change. Cognitive behavioural interventions may therefore be helpful in increasing PA in individuals with mental health conditions.

There have been relevant systematic reviews conducted in this area which have examined the relationship between mental health, PA, and adherence (Rosenbaum, Tiedemann, Sherrington, Curtis, \& Ward, 2014; Rosenbaum, Tiedemann, Stanton, et al., 2016; Firth, Rosenbaum, Stubbs, Gorczynski, Yung, \& Vancampfort, 2016; Stonerock, Hoffman, Smith \& Blumenthal, 2015; Stubbs et al., 2016; Vancampfort, et al., 2017). However, these reviews examine the impact of PA on individuals with mental health conditions, rather than examining how cognitive behavioural techniques can be used to enhance the effectiveness of PA interventions. The aim of the present review is to assess if and how the use of cognitive behavioural interventions increases adherence to PA in adults with mental health conditions.

\section{METHODS}

The protocol for this systematic review was registered $24^{\text {th }}$ April 2017 on the PROSPERO database prior to conducting this review (CRD42017057918) and can be accessed at https://www.crd.york.ac.uk/PROSPERO/display record.asp?ID=CRD42017057918. Reporting has been conducted as per the PRISMA statement (Moher, Liberati, Tetzlaff, \& Altman, 2009).

\section{ELIGIBILITY CRITERIA}

To be included in this review, studies had to (1) contain a behaviour change intervention which targeted physical activity using cognitive behavioural/psychological approaches; (2) be delivered to adults aged over 18 with a diagnosis of a mental health condition as defined by relevant editions of the DSM or ICD-10 (3) reported adherence to the intervention; (4) be a Randomised Controlled Trial (RCT) or cluster RCT(s), quasi-experimental, or studies with 
pre and post assessment data were included. Comparison groups included control groups who receive no intervention or usual treatment. Studies without a control group were eligible for inclusion provided pre and post data were available.

Studies were excluded if they were delivered to children or adolescents. Studies which focused on chronic health or physical conditions were excluded although papers which stated participants had comorbid health conditions were considered based on meeting the other eligibility criteria. Interventions that did not have a psychological or behavioural element, or were not behaviour change focused were not included. There was no exclusion based on the duration of intervention, length of follow up or format of intervention. Studies were excluded if they were not available in English, due to practical limitations. Qualitative studies were excluded since it was not within the scope of this review to examine qualitative data. Systematic reviews and study protocols were excluded, as were conference abstracts and papers where no full-text was available.

\section{INFORMATION SOURCES AND SEARCH}

Electronic searches were performed in the following databases from the year of inception to May 2017: MEDLINE, CINAHL, Cochrane Library (Trials), SPORTDiscus and PsycINFO. The following search terms were entered in each database: ("Motivational interviewing" OR "Cognitive interventions" OR Behaviour Therapy OR Cognition Therapy OR "Cognitive Behaviour Therapy" OR “Cognitive Behavioural Therapy" OR Cognitive Psychotherapy OR Cognitive Therapy OR Psychotherapy OR Behaviour Change OR Intervention OR treatment OR "Goal setting” OR “Self-monitoring”) AND (Adherence OR Compliance OR Concordance OR "Noncompliance" OR "Non Adherence" OR Engagement) AND ("Physical activity" OR "Leisure activity" OR Exercise OR Running OR Jogging OR Swimming OR Sport OR Cycling OR Inactivity OR Sedentary) AND (Lifestyle OR Gym OR outpatient OR structured exercise) AND ("Mental health" OR "Psychological wellbeing" OR "Mental well-being" OR "Mental wellbeing" OR Anxiety OR Depression OR Psychosis OR Schizophrenia OR Dementia). In addition, hand searches of reference lists and most recent reviews (Rebar \& Taylor, 2017; 
Glowacki et al., 2017; Rosenbaum et al., 2014; Schuch et al., 2016) were conducted to identify additional relevant studies.

\section{STUDY SELECTION}

After the removal of duplicates, all the remaining titles generated from the search were screened. Articles were rejected on initial screening if the reviewers could determine from the title that the articles were an inappropriate design. Titles and abstracts were then screened using the inclusion/exclusion criteria. If an abstract did not provide sufficient exclusion information then the article was obtained for full-text screening. All searches were performed by one investigator and a second reviewer checked a random set of $20 \%$ studies (using the true random number generator at www.random.org), to assess agreement regarding whether they met the inclusion criteria. Where any dubiety remained a third author would adjudicate. The final list of included articles was reached through consensus.

\section{DATA EXTRACTION}

Data were extracted by the principle investigator using a data extraction form. Data were extracted from the method and results sections of the included studies. The following information was extracted for all included studies: study design and method, country, participants (sample size, age, gender, cultural background when reported and diagnosis), intervention (delivery, timing, content and duration), outcome measures and results.

\section{QUALITY ASSESSMENT OF SELECTED STUDIES}

An analysis of the methodological quality of each study included in this review was performed, using the Quality Assessment Tool for Quantitative studies, developed by the Effective Public Health Practice Project, Canada (Thomas, Ciliska, Dobbins, \& Micucci, 2004). This tool was selected as it can be used for a variety of quantitative designs, such as RCTs, quasi-experimental studies and uncontrolled studies (Jackson \& Waters, 2005) and has been reported to have construct and content validity (Armijo-Olivo, Stiles, Hagen, Biondo, \& Cummings, 2012). This tool assesses the following domains: selection bias, study 
design, confounders, blinding, data collection methods, withdrawals and dropouts, intervention integrity, and statistical analyses. Each domain was rated as either strong, moderate or weak, and the domain scores were averaged to provide a total score to determine the strength of the quality of evidence. Lead author assessed all of the included studies, whilst the two other authors assessed $20 \%$ each of the included studies at each phase. Level of agreement was discussed between authors, and where dubiety remained a third author would also review, with final adjudication going with majority view. However, dubiety was very rare.

\section{DATA ANALYSIS}

A narrative review of all studies was conducted due to the methodological and clinical heterogeneity between the studies. The focus of the review was to summarise key findings pertinent to the research question (Ferrari, 2015). Harvest plot (Ogilvie et al., 2008), was constructed to assist the process of synthesis and provide a visual representation of evidence according to whether the interventions favoured the control, the intervention or no difference; how significant the finding was, and whether the effect was low, moderate or high. Where no comparison was available the outcome was excluded from the synthesis.

\section{$\underline{\text { RESULTS }}$}

\section{STUDY SELECTION}

In total, 1253 studies were identified through the search. An additional 12 papers were identified through hand searches. 937 papers remained after duplicates were removed. This number was reduced to 56 through the screening of titles and abstracts. The full-texts of these 56 papers were reviewed using the inclusion/exclusion criteria. Of the full-text papers, 10 met the inclusion criteria. The full results of the search and reasons for exclusion can be seen in the PRISMA flowchart (Figure 1). 


\section{STUDY CHARACTERISTICS}

The studies came from seven countries: Canada, Brazil, Italy, Sweden, UK $(n=2)$, USA $(n=2)$ and Australia $(n=2)$. Methodological quality of the individual studies ranged from low to high, and taken together constituted weak to moderate evidence. Four of the included studies targeted populations with severe mental illnesses, such as schizophrenia, psychosis and other psychotic illnesses; three studies were focused on anxiety and depressive disorder; one study included participants with alcohol dependency, one with OCD and one with exhaustion disorder. Sample sizes ranged from $13-347$, with four of the studies having sample sizes over 100 . The duration of the studies varied from 10 weeks to 12 months, with the number of sessions in which the behavioural interventions was delivered ranging from 4 sessions to 24 sessions. Follow up periods ranged from 6 months -18 months, although only 6 studies examined the effect of the intervention beyond the intervention period. On average studies consisted of 12 intervention sessions, usually delivered on a weekly basis. PA was the sole targeted behaviour in eight of the included studies. In the other two studies PA was reported alongside diet. This was because the main purpose of increasing PA was principally as a means of weight management rather than to reduce psychological symptoms. For further detail of individual interventions and study characteristics (eg country, sample size etc) please see table 1.

\section{INTERVENTIONS}

Self-monitoring of behaviour was a common feature of the interventions, with interventions utilising diaries and pedometers (Attux et al., 2013; Brown et al., 2014; Duda et al., 2014; Goracci et al., 2016; Merom et al., 2008). Goal setting was also a commonly used cognitivebehavioural strategy implemented in the interventions (Brown et al., 2014; Duda et al., 2014; Lindegard et al., 2015; Lovell et al., 2014). The use of motivational interviewing was implemented in two of the studies (Curtis et al., 2016; Duda et al., 2014) and psychoeducation featured in three of the studies (Attux et al., 2013; Beebe et al., 2011; 
Lovell et al., 2014). Two of the interventions combined group CBT with a PA intervention (Merom et al., 2008; Rector et al., 2015).

The majority of the interventions were delivered as an adjunct to supervised exercise programmes or offered access to group activities (Attux et al., 2013; Brown et al., 2014; Curtis et al., 2016; Duda et al., 2014; Lindegard et al., 2015; Lovell, et al., 2014; Rector et al., 2015). Three studies focused on increasing PA through walking (Beebe et al., 2011; Goracci et al., 2016; Merom et al, 2008).

\section{MEASUREMENT OF PHYSICAL ACTIVITY}

All of the studies measured PA using self-reported measures. The International Physical Activity Questionnaire (IPAQ) was used the most frequently, with three studies using either the full or short form version (Attux et al., 2013; Curtis et al., 2016; Lovell et al., 2014). Other questionnaire measures included the 7-Day Physical Activity Recall (PAR) (Duda et al., 2014), The Paffenbarger Physical Activity Questionnaire (Goracci et al., 2016), The Active Australia Questionnaire (Merom et al., 2008) and Saltin-Grimby Physical Activity Level Scale (Lindegård, Jonsdottir, Börjesson, Lindwall, \& Gerber, 2015). Two studies used a measure of minutes walked (Beebe et al., 2011; Merom et al., 2008). None of the included studies used an objective measure of PA (i.e. pedometers or accelerometers).

\section{EFFECT ON PHYSICAL ACTIVITY}

Of the included studies, four reported significant improvements in PA (Attux et al., 2013; Curtis et al., 2016; Duda et al., 2014; Merom et al., 2008). However, of these studies, only two reported significant effects of the intervention (Curtis et al., 2016; Merom et al., 2008). Four did not report a significant change in levels of PA (Beebe et al., 2011; Brown et al., 2014; Lovell et al., 2014; Rector, Richter, Lerman, \& Regev, 2015). Two studies did not report changes in PA, even though measures had been taken at baseline and follow up (Goracci et al., 2016; Lindegård et al., 2015). 


\section{ADHERENCE OUTCOMES}

The method of measuring adherence to the interventions in each of the included studies is presented in Table 1. The most common measure of adherence was attendance ( 5 studies, range $39 \%-79 \%$ ); followed by attrition (3 studies, range $49.5 \%-78.1 \%$ ); only one study used a self-reported exercise log and another used adherence to physical activity guidelines.

The reported levels of adherence ranged from $39 \%-80.56 \%$; with 7 of the included studies reporting adherence higher than 60\% (Attux et al., 2013; Brown et al., 2014; Curtis et al., 2016; Goracci et al., 2016; Lovell et al., 2014; Merom et al., 2008; Rector et al., 2015). The highest level of adherence to the intervention was reported in Rector et al. (2015) and the lowest level of adherence was reported in Beebe et al. (2011). The studies that reported the greatest level of effectiveness of the intervention (Curtis et al., 2016; Merom et al., 2008) reported adherence levels of $62 \%$ and $55 \%$ respectively. However, as adherence to the intervention was measured in a variety of different ways, it was not possible to meaningfully compare adherence rates across the studies included in this review.

\section{DISCUSSION}

The aim of this systematic review was to assess the effectiveness of cognitive-behavioural interventions at increasing adherence to PA in people with mental health conditions. Due to the heterogeneity in the study designs and mental health conditions targeted it is difficult to draw strong conclusions. Further, the majority of the studies did not report significant changes in levels of PA. This is consistent with the wider evidence that suggests changing PA behaviour is complex, with many interventions targeted at adults reporting small effect sizes (Rhodes, Janssen, Bredin, Warburton, \& Bauman, 2017).

Changing PA behaviour in people with mental health conditions appears to be particularly challenging. However, the majority of the studies here reported adherence rates above $60 \%$. Given that between $40-50 \%$ of adults that begin an exercise program drop out within 6 months (Dishman, 1991; Richardson et al., 2005), the results of this review can be interpreted as an indicator of the positive potential of cognitive behavioural interventions at 
improving adherence to PA in this cohort. Cognitive behavioural interventions are effective, but only moderately. This is important to understand, as future interventions are much more likely to become sustainable if they meet realistic expectations (Shelton, Cooper \& Stirman; 2018).

Regarding adherence rates within the individual studies, Merom et al's (2008) data went as expected with non-completers demonstrating significantly lower amounts of PA than completers. Brown et al. (2014) also found that the intervention was more effective for participants with better adherence. These results are important because they suggest that adherence to the intervention is an important factor in increasing levels of PA. Similar findings have been found elsewhere: O'Halloran et al. (2014) found that motivational interviewing (MI) had a small but positive effect on self-reported PA, with the effect increasing with levels of participation in MI. This highlights the importance of monitoring all aspects of adherence in intervention studies.

Given the variability in measurement of PA, it was not possible to meaningfully compare adherence rates between studies. This is unsurprising as no gold standard way of measuring adherence to PA has been established (Nyboe \& Lund, 2013). This hinders the understanding of adherence to PA, particularly in mental health populations.

Most of the included studies relied on self-report measures of PA, which are subject to recall and social desirability bias, which can lead to over or underestimations of PA (Rhodes et al., 2017). Non self-report measures of PA, such as accelerometers, are considered more accurate at measuring actual levels of PA, as findings suggest that self-report measures of adherence to PA are much higher than those that are objectively measured (Prince et al., 2008). Therefore, it is recommended that non-subjective measures should be used in combination with self-report measures, particularly in studies which aim to measure the percentage of participants meeting PA guidelines or actual levels of activity. 
Beyond the benefits to mental health, PA is beneficial for improving physical health, which is particularly relevant to people with mental health conditions, as they are at a significantly greater risk of comorbid conditions, such as heart disease, obesity and diabetes (Nocon et al., 2008). Of the included studies, very few made reference to any co-morbid health-related issues present in the participants under study. In light of this, other outcomes, such as quality of life, sleep quality, self-esteem etc. may be valuable when examining PA interventions, particularly in mental health populations, as the benefits that come from PA are not necessarily just physical (Schuch, Vancampfort, Rosenbaum, et al., 2016). It is possible that psychological benefits, such as improved self-esteem, body image and positive feelings, can accrue without a change in physical fitness. However, in the included studies quality of life outcomes were not always measured, therefore an analysis of the effects was not within the scope of this paper, but something that could be considered in future research.

Taking into consideration the nature of complex behavioural change interventions and the fact that terms such as "cognitive" or "motivational" can be used to describe a range of techniques for eliciting behaviour change, it is unsurprising that the included interventions varied in their content and delivery. The majority of the included studies also only provided brief descriptions of the interventions, which often lacked detail, for example, stating that techniques such as goal setting or self-regulation would be used, but not stating how. This made identifying the specific behavioural change techniques and how they were utilised very challenging. This is a recurring issue within behaviour change intervention studies, as noted by Michie, Fixsen, Grimshaw, and Eccles (2009). Complex behaviour change interventions are not well described in journal articles, and when they are the terminology used is often inconsistent. One way around this problem would be for authors of interventions to publish details online. That way, authors would be able to refer to this detail in publications, saving space in journal articles, and fellow researchers and clinicians alike would be better able to understand and replicate where appropriate. 
As highlighted by the quality assessment, the overall methodological quality of the included studies was moderate to weak. This can be attributed to the particular challenges that are faced in designing methodologically robust studies for people with mental health conditions. RCTs are considered the "gold standard" design for trialling intervention efficacy, however in the community and clinical settings person level randomisation is not always possible (Landsverk, Brown, Reutz, Palinkas, \& Horwitz, 2011). The screening and methods of recruitment of participants also threaten the generalisability of the results. For the most part the included studies screened participants for suitability or had very specific inclusion/exclusion criteria, and as a result, the participants may not be truly representative of the general mental health population (Borschmann et al. 2014). Another challenge in developing robustly designed trials of psychological interventions is in blinding. Whilst in medical interventions placebo treatments can be used to blind participants and practitioners, it is almost impossible to blind participants and practitioners from interventions which involve exercise and psychological interventions (Feliu-Soler et al., 2017; Shean, 2014). One long term solution would be for policy makers to take a different perspective of the research hierarchy when considering 'real world' evidence, and place a higher value on observational research conducted in appropriate complex environments. There has certainly been progress in this regard, with a much wider recognition of the limitations of reductionist thinking in relation to multifactorial community interventions (Shelton, Cooper \& Stirman; 2018). A less radical method would of course be to conduct cluster randomised trials (Hemming et al., 2017).

Finally, there was considerable variation in a) the duration of the interventions and in b) the length of follow-up in the included studies. In relation to the intervention duration, again it is difficult to compare studies due to their heterogeneity, and so, despite the intuitive appeal, it is not possible from these studies to say whether longer interventions lead to better adherence. To answer this question, the intervention would need to be standardised and impact monitored over varying lengths of time. The law of diminishing returns would suggest 
an optimal amount of intervention is likely (Stebbins, 1944). For example, patients referred to chaplains for their spiritual needs seem to benefit more from having two sessions as opposed to one, and benefit more again for three sessions as opposed to two, but don't appear to improve further for having more than three (Snowden, et al., 2018). In fact, benefit reduces at four. Mental health could be different though, as there is evidence of slow but continuous benefit from psychotherapy (Falkenström, Josefsson, Berggren, \& Holmqvist, 2016). Dedicated research is need here to establish any 'dose' of optimal support for people with mental health problems adhering to lifestyle change to incorporate more physical activity.

In relation to long term impact, only six of the included studies examined impact of the intervention beyond the initial intervention period. Very few studies have evaluated long-term PA behaviour change (Fjeldsoe, Neuhaus, Winkler, \& Eakin, 2011). There is a number of reasons why there has been a lack of research into the maintenance of PA, postintervention, such as publication bias for successful interventions (Ferrari, 2015) and the simple fact that there are more short research programmes than there are longer ones. Most concerningly, funding is very difficult to obtain to support long term interventions.

Governments and third sector providers alike appear trapped in short term thinking commensurate with their terms of office and so long-term projects are rarely funded even when there is overwhelming evidence of their efficacy. The long-term impact of behaviour change interventions is therefore largely unknown, and is likely to remain so without considerable shift in the way public services are funded.

\section{LIMITATIONS}

A limitation of this review was the range of different conceptualisations of adherence. Because there was wide variation in interpretation and measurement of adherence in the reviewed papers, there is a clear risk that the different interpretations may not have been conceptually comparable. A more restrictive approach to inclusion/exclusion criteria at selection stage would likely have concluded with a more straightforward interpretation. By 
setting the bar for inclusion criteria very high it is easy to conclude that 'more evidence is needed'. However, this would not have been a fair representation of the literature. The authors instead concluded that a broad inclusion approach was defensible because despite the heterogeneity, the papers were all measuring similar elements of adherence. Further, this narrative synthesis highlighted the complexity of the issue of measuring adherence to physical activity, hopefully encouraging future researchers to consider the concept very carefully. The elements suggested by Hawley-Hague, Horne, Skelton, and Todd (2016) could help with standardisation here: completion/retention, frequency, duration and intensity. This review also has several practical limitations. Although checked by all, the search of the literature was conducted predominately by the lead author, as was data extraction. The search was limited to studies which were published in English.

\section{CONCLUSION}

In conclusion, the studies included in this review varied considerably in terms of their design, delivery, and content. This heterogeneity made drawing conclusions about the effectiveness of cognitive behavioural interventions difficult. However, all the studies reported higher than average adherence to PA, which suggests that cognitive behavioural interventions have a limited but positive effect on increasing adherence to PA in mental health populations. Future prospective longitudinal research should be constructed to examine the long-term effects of cognitive behavioural interventions on the adherence and maintenance of physical activity in people with a range of mental health problems. The research should be constructed with reporting guidelines in mind. That way, the findings, including the details and effect size of the intervention, will be more easily synthesised with comparable research, creating transferable knowledge of both the intervention and its outcome.

\section{REFERENCES}


Armijo-Olivo, S., Stiles, C. R., Hagen, N. A., Biondo, P. D., \& Cummings, G. G. (2012). Assessment of study quality for systematic reviews: a comparison of the Cochrane Collaboration Risk of Bias Tool and the Effective Public Health Practice Project Quality Assessment Tool: methodological research. Journal of Evaluation in Clinical Practice, 18(1), 12-18. doi:10.1111/j.1365-2753.2010.01516.x

Attux, C., Martini, L., Elkis, H., Tamai, S., Freirias, A., Camargo, M., . . Bressan, R. (2013). A 6-month randomized controlled trial to test the efficacy of a lifestyle intervention for weight gain management in schizophrenia. BMC Psychiatry, 13, 60. Retrieved from http://onlinelibrary.wiley.com/o/cochrane/clcentral/articles/156/CN00864156/frame.html doi:10.1186/1471-244X-13-60

Beebe, L., Smith, K., Burk, R., McIntyre, K., Dessieux, O., Tavakoli, A., . . Velligan, D. (2011). Effect of a motivational intervention on exercise behavior in persons with schizophrenia spectrum disorders. Community Mental Health Journal, 47(6), 628636. Retrieved from http://onlinelibrary. wiley.com/o/cochrane/clcentral/articles/935/CN00860935/frame.html doi:10.1007/s10597-010-9363-8

Borschmann, R., Patterson, S., Poovendran, D., Wilson, D \& Weaver, T. (2014)Influences on recruitment to randomised controlled trials in mental health settings in England: a national cross-sectional survey of researchers working for the Mental Health Research Network. BMC Medical Research Methodology, 23, 14, 1. https://doi.org/10.1186/1471-2288-14-23

Brown, R., Abrantes, A., Minami, H., Read, J., Marcus, B., Jakicic, J., . . Stuart, G. (2014). A preliminary, randomized trial of aerobic exercise for alcohol dependence. Journal of Substance Abuse Treatment, 47(1), 1-9. Retrieved from http://onlinelibrary.wiley.com/o/cochrane/clcentral/articles/988/CN00987988/frame.html doi:10.1016/j.jsat.2014.02.004

Caspersen, C. J., Powell, K. E., \& Christenson, G. M. (1985). Physical activity, exercise, and physical fitness: definitions and distinctions for health-related research. Public Health Reports, 100(2), 126-131.

Cooney, G. (2013). Exercise for depression. Journal of Evidence-Based Medicine, 6(4), 307308. doi:10.1111/jebm.12076

Craft, L. L., \& Perna, F. M. (2004). The Benefits of Exercise for the Clinically Depressed. Primary Care Companion Journal of Clinical Psychiatry, 6(3), 104-111.

Crone, D., Heaney, L., \& Owens, C. S. (2009). 10 Physical activity and mental health. Physical activity and health promotion: Evidence-based approaches to practice, 198.

Curtis, J., Watkins, A., Rosenbaum, S., Teasdale, S., Kalucy, M., Samaras, K., \& Ward, P. B. (2016). Evaluating an individualized lifestyle and life skills intervention to prevent antipsychotic-induced weight gain in first-episode psychosis. Early Intervention in Psychiatry, 10(3), 267-276. doi:10.1111/eip.12230

Daley, A. (2008). Exercise and Depression: A Review of Reviews. Journal of Clinical Psychology in Medical Settings, 15(2), 140. doi:10.1007/s10880-008-9105-z

Dishman, R. K. (1991). Increasing and maintaining exercise and physical activity. Behavior Therapy, 22(3), 345-378. doi:http://dx.doi.org/10.1016/S0005-7894(05)80371-5

Duda, J. L., Williams, G. C., Ntoumanis, N., Daley, A., Eves, F. F., Mutrie, N., . . Jolly, K. (2014). Effects of a standard provision versus an autonomy supportive exercise referral programme on physical activity, quality of life and well-being indicators: A cluster randomised controlled trial. The International Journal of Behavioral Nutrition and Physical Activity, 11. doi:10.1186/1479-5868-11-10

Falkenström, F., Josefsson, A., Berggren, T., \& Holmqvist, R. (2016). How much therapy is enough? Comparing dose-effect and good-enough models in two different settings. Psychotherapy, 53(1), 130-139. https://doi.org/10.1037/pst0000039

Faulkner, G., Gorczynski, P., \& Arbour-Nicitopoulos, K. (2013). Exercise as an adjunct treatment for schizophrenia. In P. Ekkekakis, D. B. Cook, L. L. Craft, S. N. CulosReed, J. L. Etnier, M. Hamer, K. A. Martin Ginis, J. Reed, J. A. J. Smits, M. Ussher, 
P. Ekkekakis, D. B. Cook, L. L. Craft, S. N. Culos-Reed, J. L. Etnier, M. Hamer, K. A. Martin Ginis, J. Reed, J. A. J. Smits, \& M. Ussher (Eds.), Routledge handbook of physical activity and mental health. (pp. 541-555). New York, NY, US: Routledge/Taylor \& Francis Group.

Feliu-Soler, A., Pascual, J. C., Elices, M., Martín-Blanco, A., Carmona, C., Cebolla, A., et al. (2017). Fostering self-compassion and loving- kindness in patients with borderline personality disorder: a randomized pilot study. Clinical Psychology \& Psychotherapy, 24(1), 278-286

Ferrari, R. (2015). Writing narrative style literature reviews. Medical Writing, 24(4), 230-235. doi:10.1179/2047480615Z.000000000329

Firth, J., Rosenbaum, S., Stubbs, B., Gorczynski, P., Yung, A. R., \& Vancampfort, D. (2016, October 1). Motivating factors and barriers towards exercise in severe mental illness: A systematic review and meta-analysis. Psychological Medicine. Cambridge University Press. https://doi.org/10.1017/S0033291716001732

Fjeldsoe, B., Neuhaus, M., Winkler, E., \& Eakin, E. (2011). Systematic review of maintenance of behavior change following physical activity and dietary interventions. Health Psychology, 30(1), 99.

Gidlow, C., Johnston, L. H., Crone, D., \& James, D. (2005). Attendance of exercise referral schemes in the UK: a systematic review. Health Education Journal, 64(2), 168-186.

Glover, C. M., Ferron, J. C., \& Whitley, R. (2013). Barriers to exercise among people with severe mental illnesses. Psychiatric Rehabilitation Journal, 36(1), 45.

Glowacki, K., Duncan, M., Gainforth, H., \& Faulkner, G. (2017). Barriers and facilitators to physical activity and exercise among adults with depression: A scoping review. Mental health and physical activity. 13. 10.1016/j.mhpa.2017.10.001.

Goracci, A., Rucci, P., Forgione, R., Campinoti, G., Valdagno, M., Casolaro, I., . . Fagiolini, A. (2016). Development, acceptability and efficacy of a standardized healthy lifestyle intervention in recurrent depression. Journal of Affective Disorders, 196, 20-31. Retrieved from http://onlinelibrary.wiley.com/o/cochrane/clcentral/articles/025/CN01138025/frame.html doi:10.1016/j.jad.2016.02.034

Haddad, P., Dursun, S., and Deakin, B. . (2004). Adverse Syndromes and Psychiatric Drugs: A Clinical Guide., 455-456. doi:10.1017/S0033291705244471

Hawley-Hague, H., Horne, M., Skelton, D. A., \& Todd, C. (2016). Review of how we should define (and measure) adherence in studies examining older adults' participation in exercise classes. BMJ Open, 6(6). doi:10.1136/bmjopen-2016-011560

Hemming, K., Eldridge, S., Forbes, G., Weijer, C., \& Taljaard, M. (2017). How to design efficient cluster randomised trials. BMJ (Online), 358, 1-5. https://doi.org/10.1136/bmj.j3064

Herring, M. P., Lindheimer, J. B., \& O'Connor, P. J. (2013). The Effects of Exercise Training on Anxiety. American Journal of Lifestyle Medicine, 8(6), 388-403. doi:10.1177/1559827613508542

Jackson, N., \& Waters, E. (2005). Criteria for the systematic review of health promotion and public health interventions. Health Promotion International, 20(4), 367-374. doi:10.1093/heapro/dai022

Landis, J. R., \& Koch, G. G. (1977). The Measurement of Observer Agreement for Categorical Data. Biometrics, 33(1), 159-174. doi:10.2307/2529310

Landsverk, J., Brown, C. H., Rolls Reutz, J., Palinkas, L., \& Horwitz, S. M. (2011). Design elements in implementation research: a structured review of child welfare and child mental health studies. Administration and Policy in Mental Health, 38(1), 54-63. doi:10.1007/s10488-010-0315-y

Lindegård, A., Jonsdottir, I. H., Börjesson, M., Lindwall, M., \& Gerber, M. (2015). Changes in mental health in compliers and non-compliers with physical activity recommendations in patients with stress-related exhaustion. BMC Psychiatry, 15. Nov 4;15:272. doi: 10.1186/s12888-015-0642-3.

Lovell, K., Wearden, A., Bradshaw, T., Tomenson, B., Pedley, R., Davies, L., . . Marshall, 
M. (2014). An exploratory randomized controlled study of a healthy living intervention in early intervention services for psychosis: the INTERvention to encourage ACTivity, improve diet, and reduce weight gain (INTERACT) study. The Journal of Clinical Psychiatry, 75(5), 498-505. Retrieved from http://onlinelibrary.wiley.com/o/cochrane/clcentral/articles/539/CN00992539/frame.html doi:10.4088/JCP.13m08503

Martinsen, E. W. (2008). Physical activity in the prevention and treatment of anxiety and depression. Nordic Journal of Psychiatry, 62(Suppl 47), 25-29. doi:10.1080/08039480802315640

Martin, A., Fitzsimons, C., Jepson, R., Saunders, D. H., van der Ploeg, H. P., Teixeira, P. J., ... \& Mutrie, N. (2015). Interventions with potential to reduce sedentary time in adults: systematic review and meta-analysis. Br J Sports Med, 49(16), 1056-1063.

Merom, D., Phongsavan, P., Wagner, R., Chey, T., Marnane, C., Steel, Z., . . Bauman, A. (2008). Promoting walking as an adjunct intervention to group cognitive behavioral therapy for anxiety disorders-a pilot group randomized trial. Journal Of Anxiety Disorders, 22(6), 959-968.

Michie, S., Fixsen, D., Grimshaw, J. M., \& Eccles, M. P. (2009). Specifying and reporting complex behaviour change interventions: the need for a scientific method. Implementation Science, 4, 40. doi:10.1186/1748-5908-4-40

Moher, D., Liberati, A., Tetzlaff, J., \& Altman, D. G. (2009). Preferred reporting items for systematic reviews and meta-analyses: the PRISMA statement. BMJ: British Medical Journal, 339. doi:10.1136/bmj.b2535

Naci, H., \& loannidis, J. P. A. (2013). Comparative effectiveness of exercise and drug interventions on mortality outcomes: metaepidemiological study. BMJ : British Medical Journal, 347. doi:10.1136/bmj.f5577

NICE, N. C. C. f. M. H. (2010). Depression: the treatment and management of depression in adults. NICE guideline (CG90). Leicester and London (UK): British Psychological Society and The Royal College of Psychiatrists.

Nocon, M., Hiemann, T., Muller-Riemenschneider, F., Thalau, F., Roll, S., \& Willich, S. N. (2008). Association of physical activity with all-cause and cardiovascular mortality: a systematic review and meta-analysis. European Journal of Cardiovascular Prevention and Rehabilitation, 15(3), 239-246. doi:10.1097/HJR.0b013e3282f55e09

Nyboe, L., \& Lund, H. (2013). Low levels of physical activity in patients with severe mental illness. Nordic journal of psychiatry, 67(1), 43-46. doi:10.3109/08039488.2012.675588

O'Halloran, P. D., Blackstock, F., Shields, N., Holland, A., Iles, R., Kingsley, M., . . Taylor, N. F. (2014). Motivational interviewing to increase physical activity in people with chronic health conditions: a systematic review and meta-analysis. Clinical Rehabilitation, 28(12), 1159-1171. doi:doi:10.1177/0269215514536210

Ogilvie, D., Fayter, D., Petticrew, M., Sowden, A., Thomas, S., Whitehead, M., \& Worthy, G. (2008). The harvest plot: A method for synthesising evidence about the differential effects of interventions. BMC Med Res Methodol, 8, 8. doi:10.1186/1471-2288-8-8

Picorelli, A. M. A., Pereira, L. S. M., Pereira, D. S., Felício, D., \& Sherrington, C. (2014). Adherence to exercise programs for older people is influenced by program characteristics and personal factors: a systematic review. Journal of physiotherapy, 60(3), 151-156. doi:http://dx.doi.org/10.1016/j.jphys.2014.06.012

Prince, S. A., Adamo, K. B., Hamel, M. E., Hardt, J., Gorber, S. C., \& Tremblay, M. (2008). A comparison of direct versus self-report measures for assessing physical activity in adults: a systematic review. The International Journal of Behavioral Nutrition and Physical Activity, 5, 56-56. doi:10.1186/1479-5868-5-56

Rebar, A. L., \& Taylor, A. (2017). Physical activity and mental health; it is more than just a prescription. Mental Health and Physical Activity, 13, 77-82.

Rector, N. A., Richter, M. A., Lerman, B., \& Regev, R. (2015). A pilot test of the additive benefits of physical exercise to CBT for OCD. Cognitive Behaviour Therapy, 44(4), 328-340. doi:10.1080/16506073.2015.1016448 
Rhodes, R. E., Janssen, I., Bredin, S. S. D., Warburton, D. E. R., \& Bauman, A. (2017). Physical activity: Health impact, prevalence, correlates and interventions. Psychology \& Health, 32(8), 942-975. doi:10.1080/08870446.2017.1325486

Richardson, C. R., Faulkner, G., McDevitt, J., Skrinar, G. S., Hutchinson, D. S., \& Piette, J. D. (2005). Integrating physical activity into mental health services for persons with serious mental illness. Psychiatr Serv, 56(3), 324-331. doi:10.1176/appi.ps.56.3.324

Rosenbaum, S., Tiedemann, A., Sherrington, C., Curtis, J., \& Ward, P. B. (2014). Physical Activity Interventions for People with Mental IIIness. The Journal of Clinical Psychiatry, 75(09), 964-974. https://doi.org/10.4088/jcp.13r08765

Rosenbaum, S., Tiedemann, A., Stanton, R., Parker, A., Waterreus, A., Curtis, J., \& Ward, P. B. (2016). Implementing evidence-based physical activity interventions for people with mental illness: An Australian perspective. Australasian Psychiatry, 24(1), 49-54. https://doi.org/10.1177/1039856215590252

Samdal, G. B., Eide, G. E., Barth, T., Williams, G., \& Meland, E. (2017). Effective behaviour change techniques for physical activity and healthy eating in overweight and obese adults; systematic review and meta-regression analyses. International Journal of Behavioral Nutrition and Physical Activity, 14(1), 42. doi:10.1186/s12966-017-0494-y

Schuch, F. B., Vancampfort, D., Richards, J., Rosenbaum, S., Ward, P. B., \& Stubbs, B. (2016). Exercise as a treatment for depression: A meta-analysis adjusting for publication bias. Journal of Psychiatric Research, 77, 42-51. doi:https://doi.org/10.1016/j.jpsychires.2016.02.023

Schuch, F. B., Vancampfort, D., Rosenbaum, S., Richards, J., Ward, P. B., \& Stubbs, B. (2016). Exercise improves physical and psychological quality of life in people with depression: A meta-analysis including the evaluation of control group response. Psychiatry research, 241, 47-54. doi:10.1016/j.psychres.2016.04.054

Shean, G. (2014) Limitations of Randomized Control Designs in Psychotherapy ResearchAdvances in Psychiatry. Volume 2014, Article ID 561452, 5 pages. http://dx.doi.org/10.1155.2014.561452

Shelton, R. C., Cooper, B. R., \& Stirman, S. W. (2018). The Sustainability of EvidenceBased Interventions and Practices in Public Health and Health Care. Annual Review of Public Health, 39(1), 55-76. https://doi.org/10.1146/annurev-publhealth-040617014731.

Snowden, A., Lobb, E. A., Schmidt, S., Swing, A., McFarlane, C., \& Logan, P. (2018). What's on your mind? The only necessary question in spiritual care. Journal of the Study of Spirituality, 8(1). https://doi.org/https://doi.org/10.1080/20440243.2018.1431031

Stebbins, J. (1944). The law of diminishing returns. Science, 99(2571), 267-271. https://doi.org/10.1126/science.99.2571.267

Stonerock, G. L., Hoffman, B. M., Smith, P. J., \& Blumenthal, J. A. (2015). Exercise as Treatment for Anxiety: Systematic Review and Analysis. Annals of Behavioral Medicine, 49(4), 542-556. https://doi.org/10.1007/s12160-014-9685-9

Stubbs, B., Vancampfort, D., Rosenbaum, S., Ward, P. B., Richards, J., Soundy, A., ... Schuch, F. B. (2016, January 15). Dropout from exercise randomized controlled trials among people with depression: A meta-analysis and meta regression. Journal of Affective Disorders. Elsevier. https://doi.org/10.1016/j.jad.2015.10.019

Thomas, B. H., Ciliska, D., Dobbins, M., \& Micucci, S. (2004). A Process for Systematically Reviewing the Literature: Providing the Research Evidence for Public Health Nursing Interventions. Worldviews on Evidence-Based Nursing, 1(3), 176-184. doi:10.1111/j.1524-475X.2004.04006.x

Vancampfort, D., Firth, J., Schuch, F. B., Rosenbaum, S., Mugisha, J., Hallgren, M., ... Stubbs, B. (2017). Sedentary behavior and physical activity levels in people with schizophrenia, bipolar disorder and major depressive disorder: a global systematic review and meta-analysis. World Psychiatry, 16(3), 308-315. https://doi.org/10.1002/wps.20458

World Health Organisation. (2014). Premature death among people with severe mental 
disorders. Retrieved from

http://www.who.int/mental_health/management/info_sheet.pdf

World Health Organization. (2018). What is Physical Activity. Retrieved from

https://www.who.int/news-room/fact-sheets/detail/physical-activity

World Health Organisation. (2019). Mental, behavioural or neurodevelopmental disorders.

Retrieved from https://icd.who.int/browse11//-

m/en\#/http\%3A\%2F\%2Fid.who.int\%2Ficd\%2Fentity\%2F334423054 

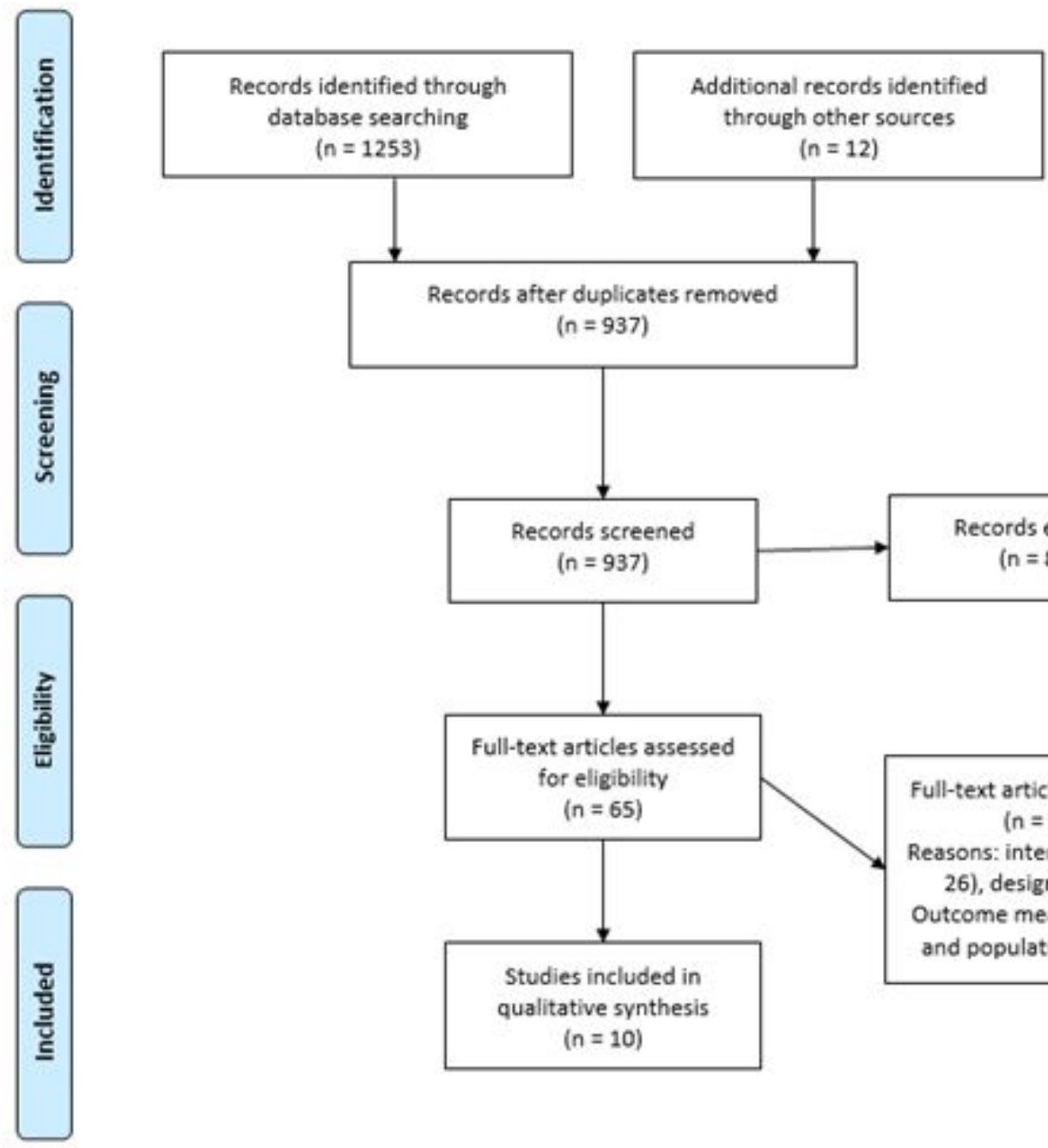

$$
\text { ( } n=937)
$$
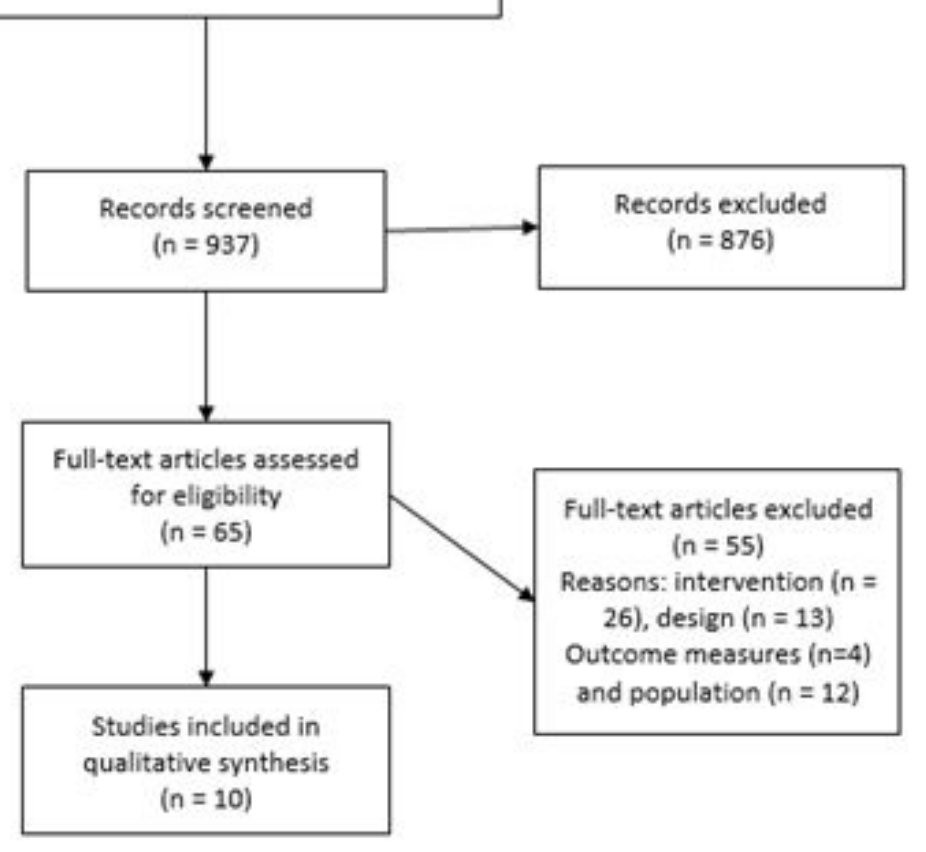

Figure 1 PRISMA Flow Chart 
Table 1 Study Characteristics

\begin{tabular}{|c|c|c|c|c|c|c|c|c|c|}
\hline $\begin{array}{l}\text { Study \& } \\
\text { country }\end{array}$ & Design & Participants & Diagnosis & $\begin{array}{l}\text { Comorbidities } \\
\text { Declared? }\end{array}$ & $\begin{array}{l}\text { Intervention } \\
\text { Duration }\end{array}$ & $\begin{array}{l}\text { Follow } \\
\text { up }\end{array}$ & $\begin{array}{l}\text { Intervention } \\
\text { (Frequency/Components) }\end{array}$ & $\begin{array}{l}\text { PA } \\
\text { Measure }\end{array}$ & $\begin{array}{l}\text { Adherence } \\
\text { Measure }\end{array}$ \\
\hline $\begin{array}{l}\text { Attux et al. } \\
\text { (2013) } \\
\text { Brazil }\end{array}$ & RCT & $\begin{array}{l}\mathrm{N}=160 ; 64 \\
\text { female/96 male; } \\
\text { average age in } \\
\text { intervention group } \\
36.2(\mathrm{SD}=9.9 \text { ); } \\
60 \% \text { Caucasian, } \\
11 \% \text { Afro- } \\
\text { American; } 10 \% \\
\text { other. }\end{array}$ & Schizophrenia & No & 12 weeks & 6 months & $\begin{array}{l}12 \text { one-hour weekly group } \\
\text { sessions led by mental health } \\
\text { professionals which combined } \\
\text { behavioural techniques such as } \\
\text { the use of diaries and role play, } \\
\text { with psychoeducation } \\
\text { components. }\end{array}$ & $\begin{array}{l}\text { Self-report: } \\
\text { International } \\
\text { Physical } \\
\text { Activity } \\
\text { Questionnaire } \\
\text { (IPAQ) }\end{array}$ & $\begin{array}{l}\text { Attendance: } \\
\text { No. of } \\
\text { sessions } \\
\text { attended. }\end{array}$ \\
\hline $\begin{array}{l}\text { Beebe et al. } \\
(2011) \\
\text { USA }\end{array}$ & $\mathrm{RCT}$ & $\begin{array}{l}\mathrm{N}=97 ; \text { age } 46.9 \\
(\mathrm{SD}=2.0) ; 46 \\
\text { female/51 male; } \\
\text { Caucasian } 54.6 \% \text {; } \\
44.4 \% \text { African } \\
\text { American, } 1 \% \\
\text { Asian. }\end{array}$ & $\begin{array}{l}\text { Schizoaffectiv } \\
\text { e disorder }(n= \\
69), \\
\text { Schizophrenia } \\
(n=28)\end{array}$ & No & 20 weeks & & $\begin{array}{l}4 \text { weekly, hour-long group } \\
\text { sessions, content was based on } \\
\text { self-efficacy theory and included } \\
\text { goal setting, barrier identification } \\
\text { and behavioural prompts; Walking } \\
\text { groups met } 3 \text { times weekly for } 16 \\
\text { weeks. }\end{array}$ & $\begin{array}{l}\text { Self-report: } \\
\text { Total number } \\
\text { of minutes } \\
\text { each subject } \\
\text { walked during } \\
\text { the walking } \\
\text { groups each } \\
\text { month }\end{array}$ & $\begin{array}{l}\text { Attendance } \\
\text { and duration: } \\
\text { No of groups } \\
\text { attended and } \\
\text { no. of weeks } \\
\text { attended at } \\
\text { least one } \\
\text { group. }\end{array}$ \\
\hline $\begin{array}{l}\text { Brown et al. } \\
\text { (2014) } \\
\text { USA }\end{array}$ & $\mathrm{RCT}$ & $\begin{array}{l}\mathrm{N}=49 ; \text { age } 44.37 \\
(\mathrm{SD}=10.75) ; 22 \\
\text { females } / 27 \text { males; } \\
\text { Caucasian } \\
91.3 \% \%, 8.7 \%\end{array}$ & $\begin{array}{l}\text { Alcohol } \\
\text { dependence }\end{array}$ & $\begin{array}{l}\text { Yes: Anxiety and } \\
\text { depression }\end{array}$ & 12 weeks & 6 months. & $\begin{array}{l}12 \text { weekly aerobic exercise } \\
\text { sessions and brief } 15-20 \text { minutes } \\
\text { group behavioural sessions; } \\
\text { Exercise sessions began at } 20 \\
\text { minutes per session and gradually }\end{array}$ & $\begin{array}{l}\text { Self-report: } \\
\text { Health } \\
\text { questionnaire } \\
\text { and Physical } \\
\text { Activity }\end{array}$ & $\begin{array}{l}\text { Attendance: } \\
\text { No of sessions } \\
\text { attended }\end{array}$ \\
\hline
\end{tabular}




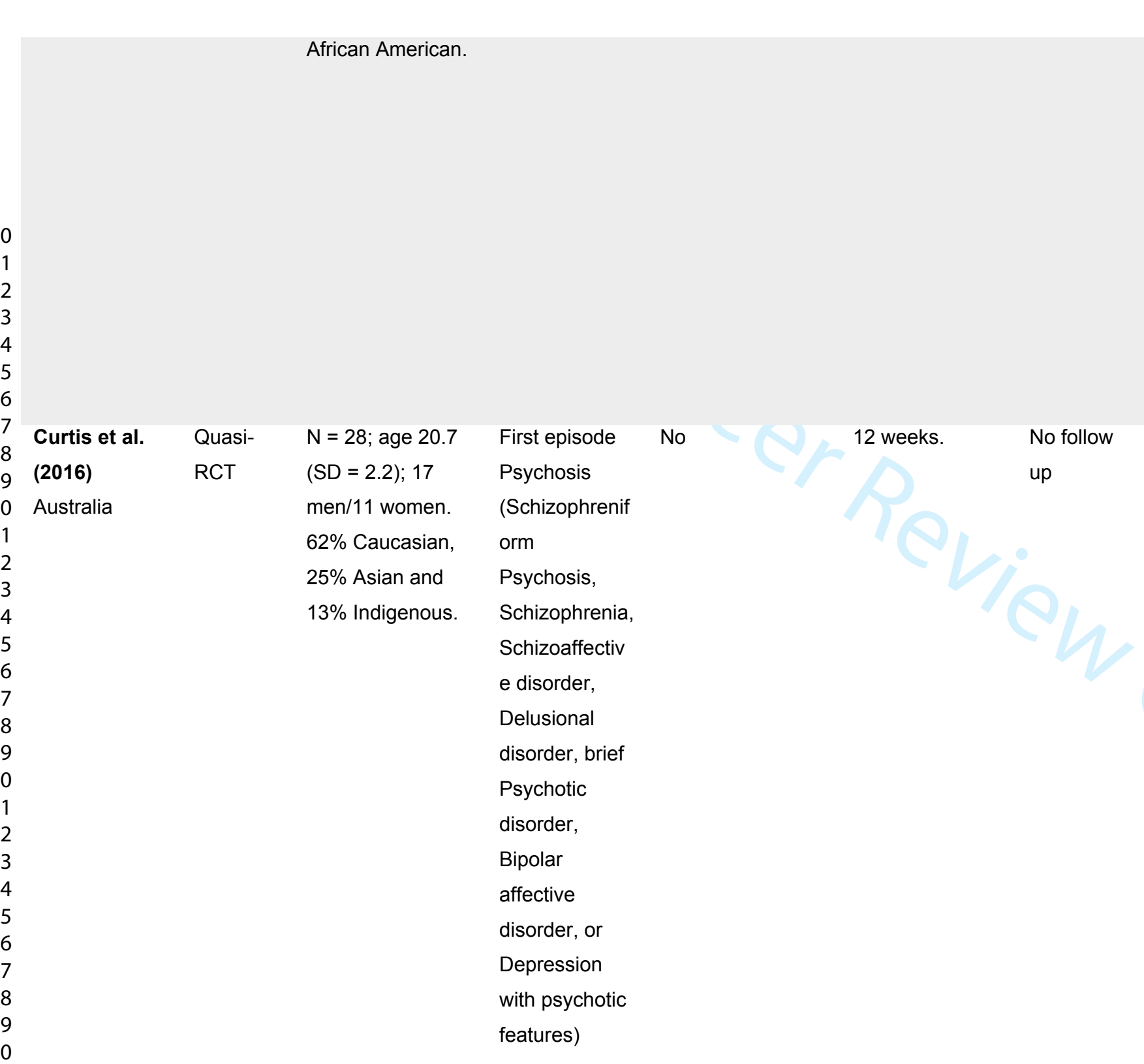

progressed to 40 minutes per session by week 12 ; Group

behavioural sessions involved cognitive and behavioural techniques such as goal setting, barrier identification and relapse prevention techniques aimed to increase motivation and adherence. Monetary incentives provided for participants who attended weekly sessions.

The intervention involved health coaching, dietetic support and supervised exercise prescriptions; delivered by a team that included a clinical nurse consultant, a dietician, an exercise physiologist and youth peer wellness coaches. The health coaching involved goal identification and motivational interviewing. Self-report:

IPAQ-SF

Screen;

Timeline

Follow Back

for Exercise 


\begin{tabular}{|c|c|c|c|c|c|c|c|c|c|}
\hline $\begin{array}{l}\text { Duda et al. } \\
\text { (2014) } \\
\text { UK }\end{array}$ & $\begin{array}{l}\text { Cluster } \\
\text { RCT }\end{array}$ & $\begin{array}{l}\mathrm{N}=347 ; 72.9 \% \\
\text { female/27.1\% } \\
\text { male; } 74.9 \% \\
\text { White British, } \\
\text { Black African or } \\
\text { Caribbean } 10.6 \% \text {, } \\
\text { South Asian } 9.5 \% \text {, } \\
\text { Mixed } 5 \% \text {. }\end{array}$ & $\begin{array}{l}\text { Probable } \\
\text { Anxiety and } \\
\text { Depression }\end{array}$ & $\begin{array}{l}\text { Yes: Two or more } \\
\text { risk factors for } \\
\text { Coronary Heart } \\
\text { Disease; Chronic } \\
\text { medical } \\
\text { conditions: } \\
\text { asthma, } \\
\text { bronchitis, } \\
\text { diabetes, } \\
\text { hypertension }\end{array}$ & 3 months & 6 months & $\begin{array}{l}\text { A Health and Fitness Advisor had } \\
\text { one-to-one contact, in person or } \\
\text { via telephone, with participants on } \\
\text { four occasions. The intervention } \\
\text { used motivational interviewing } \\
\text { techniques, such as careful } \\
\text { listening, parroting, and handling } \\
\text { resistance and double-sided } \\
\text { reflection, and Self Determination } \\
\text { Theory-based strategies. } \\
\text { Participants took part in 10-12 } \\
\text { weeks of exercise programmes } \\
\text { overseen by the HFA. }\end{array}$ & $\begin{array}{l}\text { Self-report: 7- } \\
\text { Day Physical } \\
\text { Activity Recall } \\
\text { (PAR) }\end{array}$ & $\begin{array}{l}\text { Completion: } \\
\text { Attrition level. }\end{array}$ \\
\hline $\begin{array}{l}\text { Goracci et al. } \\
\text { (2016) } \\
\text { Italy }\end{array}$ & RCT & $\begin{array}{l}N=160 ; \text { age } 49 \\
80 \% \text { female } / 20 \% \\
\text { male. }\end{array}$ & $\begin{array}{l}\text { Bi-polar } \\
\text { disorder }(\mathrm{n}= \\
105) \text { and } \\
\text { recurrent } \\
\text { Unipolar } \\
\text { Depression ( } \mathrm{n} \\
=55)\end{array}$ & No & $10-12$ weeks & 12 months & $\begin{array}{l}10 \text { weekly } 45-60 \text {-minute sessions } \\
\text { (12 if participants elected to take } \\
\text { part in the smoking cessation } \\
\text { module) all sessions included } \\
\text { cognitive and behavioural } \\
\text { techniques and homework for } \\
\text { participants, sessions were run by } \\
\text { psychiatrists and dieticians. }\end{array}$ & $\begin{array}{l}\text { Self-report: } \\
\text { The } \\
\text { Paffenbarger } \\
\text { Physical } \\
\text { Activity } \\
\text { Questionnaire }\end{array}$ & $\begin{array}{l}\text { Completion: } \\
\text { no. completing } \\
\text { program. }\end{array}$ \\
\hline $\begin{array}{l}\text { Lindegård et } \\
\text { al. (2015) } \\
\text { Sweden }\end{array}$ & Cohort & $\begin{array}{l}\mathrm{N}=69 ; \text { age } 42.6 \\
45 \text { female/24 } \\
\text { male. }\end{array}$ & $\begin{array}{l}\text { Exhaustion } \\
\text { Disorder }\end{array}$ & $\begin{array}{l}\text { Yes: Anxiety and } \\
\text { Depression }\end{array}$ & 12 months & 18 months & $\begin{array}{l}\text { The composition of the program } \\
\text { was tailored to each participant's } \\
\text { needs. Participants were allowed } \\
\text { to self-select the components } \\
\text { appropriate for their needs. The } \\
\text { frequency and duration of visits } \\
\text { were similar for all patients (on } \\
\text { average, patients had two }\end{array}$ & $\begin{array}{l}\text { Self-report: } \\
\text { Saltin-Grimby } \\
\text { Physical } \\
\text { Activity Level } \\
\text { Scale. }\end{array}$ & $\begin{array}{l}\text { Duration: } \\
\text { Level complied } \\
\text { with American } \\
\text { College of } \\
\text { Sport Medicine } \\
\text { Guidelines } \\
\text { post- } \\
\text { intervention }\end{array}$ \\
\hline
\end{tabular}




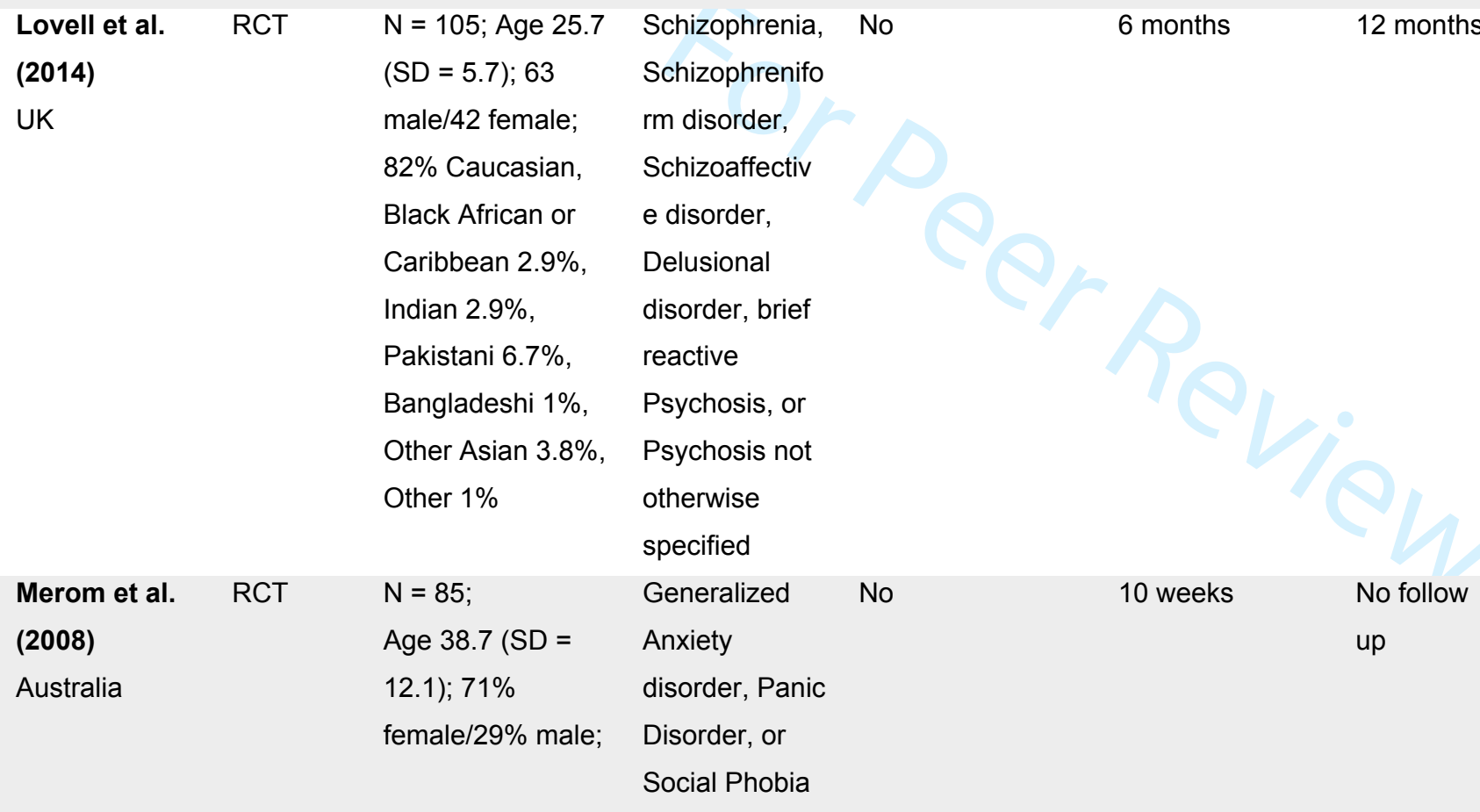

consultations lasting $1.5 \mathrm{~h}$ and 10 consultations lasting $30 \mathrm{~min}$ ). The program offered cognitive

behavioural group therapy, stress management, and Physical

Activity Counselling.

Based on Leventhal's Common

Sense Model, the intervention

contained behavioural and

motivational components, such as

psychoeducation, goal setting and

action plans. The intervention was

delivered by support, time and

recovery workers, participants

received 7 individual face-to-face

sessions over 6 months, with a

"booster" session at 9-10 months.

Group CBT, 90-min session

delivered once a week for 8

weeks by clinical psychologists.

Exercise program delivered by an

exercise trainer, with the aim to

gradually increase the 30 -minute

sessions of moderate-intensity

exercise to accumulate 150

minutes per week.

\section{Self-report: Attendance: \\ IPAQ No. of \\ sessions}

attended.

Self-report:

The Active

Australia

Attendance:

No of sessions

attended,

Questionnaire;

change in

minutes of

walking "for

exercise and

recreation" 


\begin{tabular}{|c|c|c|c|c|c|c|c|c|c|}
\hline $\begin{array}{l}\text { Rector et al. } \\
\text { (2015) } \\
\text { Canada }\end{array}$ & Cohort & $\begin{array}{l}\mathrm{N}=14 ; \text { Age } 35.54 \\
(\mathrm{SD}=8.47) ; 8 \\
\text { male/6 female; } \\
55 \% \text { Caucasian, } \\
18 \% \text { Asian, } 9 \%\end{array}$ & $\begin{array}{l}\text { Obsessive } \\
\text { Compulsive } \\
\text { Disorder } \\
\text { (OCD) }\end{array}$ & $\begin{array}{l}\text { Yes: Binge-eating } \\
\text { disorder, major } \\
\text { depressive } \\
\text { episode, phobia }\end{array}$ & 15 weeks & $\begin{array}{l}\text { No follow } \\
\text { up }\end{array}$ & $\begin{array}{l}\text { Combined CBT and physical } \\
\text { exercise delivered in a group } \\
\text { format, for } 15 \text { consecutive weeks. } \\
\text { The physical exercise involved } 12 \\
\text { weeks of aerobic exercise. }\end{array}$ & $\begin{array}{l}\text { Self-report: } \\
\text { The Physical } \\
\text { Activity } \\
\text { Readiness } \\
\text { Questionnaire }\end{array}$ & $\begin{array}{l}\text { Attendance, } \\
\text { duration and } \\
\text { intensity: Self- } \\
\text { reported } \\
\text { exercise logs. }\end{array}$ \\
\hline
\end{tabular}

East Indian and

the remaining

$18 \%$ preferred not

to specify. 
Intervention
Favours control

Favours intervention

Weight loss program

Group exercise + motivation/CB

Individualised programme

Healthy lifestyle intervention

Outcome

Weight control

Physical activity

Depression

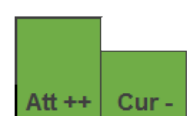

Att ++ Cur -

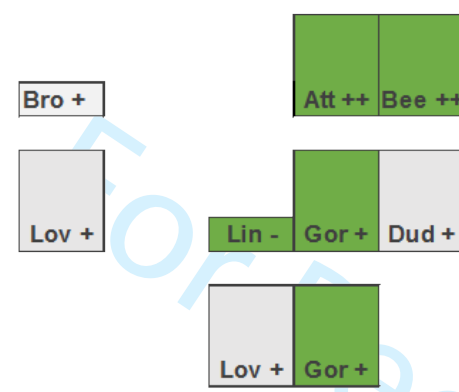

Bro +

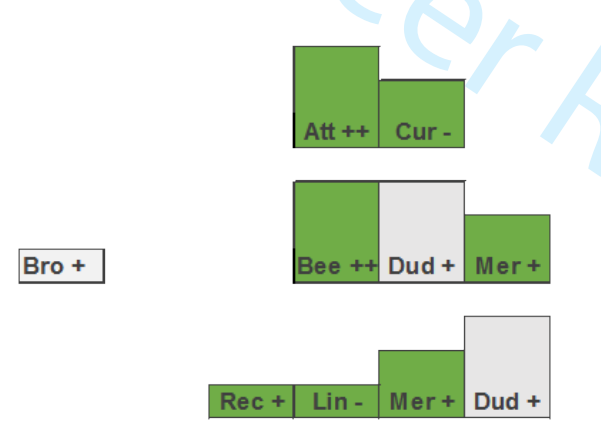

N Certainty of the evidence (GRADE)

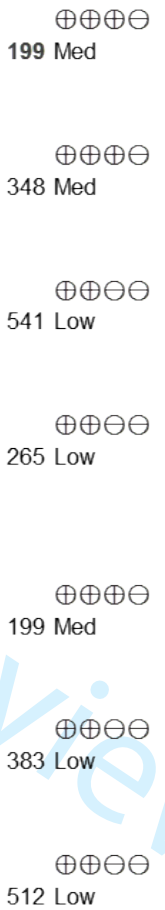

512 Low

Notes: Each bar represents a study, referenced by the first three letters of the first authors' surname, or four where further differentiation is needed.

$\begin{array}{ll}\text { Low risk of bias }++ & \text { Not significant } \\ \text { Medium risk of bias }+ & p<.10 \\ \text { High risk of bias - } & p<0.05\end{array}$

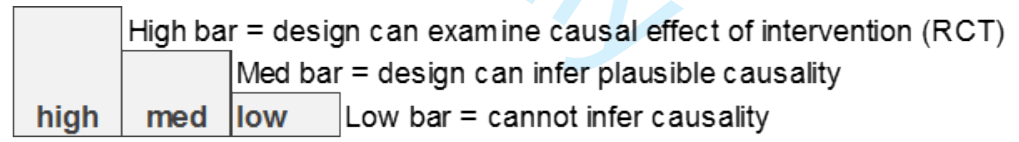

Figure 2: Harvest Plot 
